Letter to The Editor

\title{
Seroprevalence of Hepatitis B and C in Healthy Malaysian Adults: A Preliminary Report
}

\author{
Hui-min Neoh, Saberi bin Saimun, Rahman Jamal* \\ UKM Medical Molecular Biology Institute (UMBI), Universiti Kebangsaan Malaysia, Malaysia
}

\section{Article Info}

History : Received : 5 March 2019; Accepted : 17 May 2019; Available : 28 July 2019

Permalink/ DOI: https://doi.org/10.14710/jbtr.v5i1.4281

Viral hepatitis caused by Hepatitis A, B or C virus infection is a significant cause of morbidity and mortality in Malaysia. The national incidence rate for hepatitis A has dropped steadily in conjunction with successful public health measures; nevertheless, hepatitis $\mathrm{B}$ and $\mathrm{C}$ incidence and its clinical outcome remain a concern for health authorities ${ }^{1}$.

In this study, previous hepatitis $\mathrm{B}$ (HBV) and $\mathrm{C}$ (HCV) virus prevalence in healthy Malaysian adults residing in Peninsular Malaysia was determined in a serosurvey. One thousand and twenty (1020) serum samples were randomly sampled from the Malaysian Cohort biobank. The Malaysian Cohort is a national project carried out to determine risk factors and biomarkers for diseases in the Malaysian population ${ }^{2}$. For this serosurvey, samples were from participants aged 35-64 and residing in the states of Peninsular Malaysia. HBV and HCV prevalence of sampled subjects were determined using HBV surface antigen (HBsAg) and HCV antibody (HCV Ab) detection kits (RVR Diagnostics Sdn. Bhd., Malaysia), respectively. Briefly, 10ul of each tested serum was pipetted into the well of a test cartridge, which was later added with the kit's diluent reagent. The sample and diluent mixture was then incubated for 10 minutes prior reading of test result. A double band on the cartridge (one band for control, another for sample positivity) indicates a positive result, while a single band is indicative of a negative outcome. The HBsAg kit has a sensitivity and specificity of $100 \%$, while the $\mathrm{HCV}$ Ab kit has a sensitivity of $98.7 \%$ and specificity of $99.6 \%$.

\footnotetext{
* Corresponding author:

E-mail: rahmanj@ppukm.ukm.edu.my (Rahman Jamal)
}

Twenty-eight (28) or $2.8 \%$ serum samples were tested positive for $\mathrm{HBsAg}$, while 10 (1.0\%) samples were found to carry antibodies for HCV. No sample was positive for both $\mathrm{HBsAG}$ and $\mathrm{HCV} \mathrm{Ab}$. Interestingly, for the HBsAg positive samples, most $(n=14,50.0 \%)$ were from the older age group of 55-64 years old, and staying in rural areas $(n=18,64.3 \%)$. While for the $\mathrm{HCV}$ seropositive subjects, most were from the older age group of 55-64 years old $(n=5,50 \%)$, with more urbanites found to be seropositive $(n=6,60 \%)$.

The prevalence of HBsAg in Malaysians was reported to be around 5 to $7 \%$ in the $1980 \mathrm{~s}$; this was before the nationwide implementation of hepatitis $\mathrm{B}$ vaccination for all new-born infants in $1989^{3}$. Even though the vaccination drive was aimed at infants, some young adults during the 1980 s also received the vaccination; this might have subsequently lowered the seroprevalence to $2.8 \%$ as found in this study ${ }^{4}$. However, a previous report estimated $2.5 \%$ of the Malaysian population aged 15-64 years old to be positive for HCV exposure, an estimate higher than the results obtained in this study ${ }^{5}$. Despite its low prevalence, HCV seropositivity remains a healthcare concern as no vaccine is yet available; and without active screening surveillance the infected are usually diagnosed at a later stage with cirrhosis or liver cancer. In Indonesia, to our knowledge, only one study on HCV seroprevalence was perform in healthy subjects, where $2.2 \%$ were found to be $\mathrm{HCV}$ positive ${ }^{6}$; while $\mathrm{HBsAg}$ prevalence was found to be $1.1 \%$ in young adults of Singapore ${ }^{7}$.

This preliminary report shows low seroprevalence of $\mathrm{HBV}$ and $\mathrm{HCV}$ in adults residing in Peninsular Malaysia. A larger study involving representative participants for each demographic factor will be carried out in the future. 


\section{ACKNOWLEDGEMENT:}

The project is funded by the Ministry of Science, Technology and Innovation (MOSTI), Malaysia (ER05-01-02-MEB001), and also by the Ministry of Higher Education, Malaysia (PDE48). Additional funding, including infrastructure and utilities, is provided by the Universiti Kebangsaan Malaysia. We would like to thank all staff members of the Biobank Unit of The Malaysian Cohort Consortium (TMC), especially Mrs. Norliza Ismail and Mr. Zulhakim Zainuddin, for their assistance in retrieval of samples.

\section{REFERENCES:}

1. Raihan R. Hepatitis in Malaysia: Past, Present, and Future. Euroasian J Hepato-Gastroenterol 2016; 6(1):52-55.

2. Jamal R, Syed Zakaria SZ, Kamaruddin MA, Abd Jalal N, Ismail N, Mohd Kamil N, ... the Malaysian Cohort Study Group. Cohort Profile: The Malaysian Cohort (TMC) project: a prospective study of non-communicable diseases in a multiethnic population. International Journal of Epidemiology 2015; 44(2), 423-431.
3. Lopez CG. Epidemiology of persistent hepatitis B virus infection. Malays J Pathol 1985; 7:7-10.

4. Ng KP, Saw TL, Baki A, Rozainah K, Pang KW, Ramanathan M. Impact of expanded programme of immunization on hepatitis B infection in school children in Malaysia. Med Microbiol Immunol 2005; 194(3):163-168.

5. McDonald SA, Dahlui M, Mohamed R, Naning H, Shabaruddin FH, Kamarulzaman A. Projections of the current and future disease burden of hepatitis C virus infection in Malaysia. PLoS One 2015; 10(6):e0128091.

6. Pracoyo NE, Suratri MAL, Roselinda R, SetiawatyV. The Association of Hepatitis C Serological Status with Several Risk Factors in Indonesia. International Scholarly Research Notices. Volume 2016, Article ID 3018135.

7. Ang LW, Cutter J, James L, Goh KT. Seroepidemiology of hepatitis B virus infection among adults in Singapore: a 12-year review. Vaccine. 2013 Dec 17;32(1):103-10. 